Boise State University

ScholarWorks

$3-1-2013$

Women Bound to be Active: Differences in LongTerm Physical Activity Between Completers and Noncompleters of a Book Club Intervention

Jennifer L. Huberty

Arizona State University

Diane Ehlers

Arizona State University

Jason Coleman

University of Nebraska at Omaha

Yong Gao

Boise State University

Steriani Elavsky

Pennsylvania State University 


\title{
Women Bound to be Active: Differences in Long-Term Physical Activity Between Completers and Noncompleters of a Book Club Intervention
}

\begin{abstract}
Jennifer L. Huberty, Diane Ehlers, Jason Coleman, Yong Gao, and Steriani Elavsky
Background: Ideal approaches to increasing long-term physical activity (PA) adherence in women remain unclear. This study used a longitudinal mixed-methods approach to 1) determine the effectiveness of an 8-month book club intervention for increasing PA participation and self-worth, and reducing barriers at 1-year followup; and 2) identify reasons why completers and noncompleters did or did not maintain PA. Methods: One year after the cessation of Women Bound to be Active (WBA), completers (participated in posttesting; $\mathrm{n}=30$ ) and noncompleters (did not participate in posttesting; $n=22$ ) responded to questionnaires and interviews assessing their body mass index (BMI), current PA participation, barriers, and global self-worth. Results: Compared with noncompleters, completers reported decreases in BMI, higher motivation for PA, higher ratio of benefits to barriers, and more consistent PA. Both groups still reported barriers to PA, especially time; however, completers more often reported strategies for overcoming these barriers. Completers more directly discussed the impact of their improved self-worth on their PA participation. Conclusions: In the future, a greater focus on time management and self-regulation strategies should be emphasized in PA interventions, specifically those that focus on women. This may help to prevent program and long-term PA attrition.
\end{abstract}

Keywords: health promotion, health behavior, qualitative research

Despite the known benefits of physical activity (PA) and the numerous attempts researchers have made to design interventions to help women begin and maintain PA, women's PA levels have not changed significantly in the past 10 years. In 2007, $41 \%$ of women reported being inactive compared with $43 \%$ in 1998 (no leisuretime PA). Only $29 \%$ of women reported participating in regular leisure-time activity ( 3 or more sessions per week of vigorous activity lasting at least 20 minutes or 5 or more sessions per week of light/moderate activity lasting at least 30 minutes in duration) in 2007, compared with $26 \%$ in $1998 .{ }^{1}$ Interventions during the past decade have used varying approaches to facilitate increases in PA in women, including informational, behavioral, and environmental approaches. ${ }^{2}$ Although some of these approaches may be effective short-term, ${ }^{3,4}$ few have demonstrated success long-term (12 months or longer). ${ }^{5}$ To achieve health benefits, women need to be successful at maintaining and adhering to a regular PA regimen. PA lapses have been associated with decreases in psychosocial outcomes such as self-efficacy and aspects of

Huberty and Ehlers are with the School of Nutrition and Health Promotion, Arizona State University, Phoenix, AZ. Coleman is with the Dept of Health, Physical Education, and Recreation, University of Nebraska at Omaha, Omaha, NE. Gao is with the Dept of Kinesiology, Boise State University, Boise, ID. Elavsky is with the Dept of Kinesiology, The Pennsylvania State University, University Park, PA. health-related quality of life, and 39\% of women with lapses never return to PA. ${ }^{6}$ Therefore, novel intervention approaches to encourage PA behavior change in women as well as longitudinal methods for understanding factors related to long-term PA maintenance in this subpopulation are needed.

Short-term PA studies have provided evidence that women are most successful when they have social support ${ }^{2}$ and have at least a moderate level of confidence in their ability to overcome barriers and motivate themselves to be physically active. ${ }^{7}$ Other studies have suggested that women are most successful with PA behaviors long-term when they are able to set goals, specifically goals related to well-being and stress reduction, as compared with goals related to weight loss and health benefits. ${ }^{8}$ Huberty and colleagues ${ }^{9}$ have suggested that interventions should emphasize 1) increasing a woman's ability to access social support, 2) making activity a high priority in a woman's life, 3) improving or deemphasizing body image, and 4) facilitating the use of self-regulation strategies. McAuley and Blissmer ${ }^{10}$ have recommended that women's self-efficacy (ie, confidence in the ability to be physically active), along with actual participation in PA, may influence global self-esteem (self-worth). Research also provides evidence that fostering self-worth may be an effective strategy to increase PA participation in women. ${ }^{10-13}$ Self-worth involves women's satisfaction with themselves across different domains (eg, academic, social, emotional, and physical). ${ }^{14,15}$ Researchers suggest 
domain-specific approaches to improve self-worth. ${ }^{16}$ Consistent with this, most research linking self-worth and PA has focused primarily on self-worth in the physical domain, with little to no focus on nonphysical domains that may impact PA as well. ${ }^{12,13,17}$ For example, Strelan and colleagues ${ }^{18}$ concluded that women who participated in PA for reasons related to their appearance (weight, body tone, attractiveness) had lower levels of body satisfaction and self-esteem than women who participated in PA for reasons related to function (ie, health, mood, and enjoyment). It has also been reported that midlife women who have body-shape motives are significantly less active than those with nonbody shape motives. ${ }^{19}$ Based on these findings, there is a need to examine nonphysical approaches to improving self-worth and PA in women.

In an effort to engage healthy adult women to be active, Huberty and colleagues ${ }^{11}$ designed an innovative book-club intervention and tested its effectiveness in 2 separate pilot studies. Women in the first pilot study reported increased PA participation and higher perceptions of self-worth as a result of the book club approach. ${ }^{11}$ Women in the second pilot study demonstrated significant increases in self-worth and benefits relative to barriers for PA, and were more likely to meet PA recommendations in relation to a comparison group at the end of the intervention. ${ }^{20}$

In a 1-year follow-up to the first pilot study, women reported significant improvements in their self-worth and body mass index as compared with baseline. ${ }^{21} \mathrm{PA}$ levels, however, varied among participants at the 1-year follow-up. Although some women reported challenges to maintaining PA, at 1-year follow-up women remained more knowledgeable about PA and had developed strategies to overcome barriers as compared with baseline. Nevertheless, women reported ongoing barriers to PA which included 1) decreased social support at the end of the intervention, 2) competing time between PA and work/ family obligations, and 3) lack of motivation. ${ }^{21}$ More studies are needed that explore in-depth reasons women are able (or unable) to maintain PA 1 year after participation in a PA program. Ideal approaches to increasing longterm adherence in women remain unclear, ${ }^{5}$ and further longitudinal research utilizing mixed-methods techniques should explore correlates of women's PA adherence.

Therefore, in a follow-up to pilot study 2, this study used a mixed-methods approach to 1) determine if the book club (pilot study 2) was effective 1 year after the intervention ended in increasing PA participation longterm, improving the ratio of benefits relative to barriers of PA, and increasing self-worth; and 2) identify reasons why completers and noncompleters did or did not maintain PA.

\section{Methods}

Eligible participants were women who had participated in the second pilot intervention of the Women Bound to Be Active (WBA) program. ${ }^{20}$ Participants were originally recruited through newspaper advertisements, volunteered to participate, and paid $\$ 99.00$ for discussion materials, books, and pedometers. Women who could not afford to pay were able to participate in WBA at no cost through a grant from the American Heart Association. Participants were 19 years of age or older and in either the contemplation or preparation stages of PA behavior change of the Transtheoretical Model (TTM). ${ }^{22}$ Eighty-one women met the original inclusion criteria, and a total of 52 women participated in the second WBA pilot study. Details of the intervention are published elsewhere. ${ }^{11,20}$ Briefly, WBA is an 8-month cognitive behavior change program that uses a book club approach to increase PA and self-worth in women. WBA is based on the tenets of the TTM ${ }^{22}$ and Social Cognitive Theory (SCT) ${ }^{23}$ and uses strategies from these theories as points of discussion in relation to book club readings (both fiction and nonfiction books) to improve self-worth. During WBA women were encouraged to participate in lifestyle-based PA outside of the book club, but were not given a structured exercise program to follow. Instead women discussed enjoyable ways to be active and ways that would help them to continue to participate in PA long-term.

One year after the cessation of WBA ( 20 months after program began) women who completed the program (defined as completion of posttesting at the immediate end of the intervention; $\mathrm{n}=30$ ) and women who did not complete the program $(n=22)$ were sent a packet that included 1) a cover letter of consent (specific to completers or noncompleters) that explained the follow-up study and notified the women that someone would be contacting them to schedule an interview, 2) a copy of the interview questions to allow women to think about the answers before the interview, and 3) the questionnaires they had completed as WBA participants. Potential participants were asked to complete the questionnaires and send them back in the self-addressed envelope in their packet. Completion of the questionnaires and consent to participate in the interview served as informed consent. The study was approved by the Institutional Review Board at a Midwestern University Medical Center.

\section{Instruments}

Demographics Questionnaire. The demographics questionnaire was adapted from Howley and Franks ${ }^{24}$ and was used to obtain age, ethnicity, and self-reported height and weight at follow-up. Self-reported height and weight have been determined valid in populations of middle-aged adults. ${ }^{25}$ At baseline and postintervention, height and weight were measured using standardized procedures. ${ }^{20}$ Body mass index (BMI, $\mathrm{kg} / \mathrm{m}^{2}$ ) was calculated using measured/self-reported height and weight.

PA. PA was assessed using the 1-year Modifiable Activity Questionnaire (MAQ). ${ }^{26}$ Participants reported the months in which they had been active (both leisure and occupational) and the mode, frequency, and duration of the activities. PA is calculated in terms of leisure and occupational hours per week, leisure and occupational MET-hours per week, and total hours and MET-hours per week. The MAQ is reliable and valid in several 
populations and studies. ${ }^{26,27}$ The test-retest reliability was 0.88 from the original reliability study. ${ }^{26}$

Benefits to Barriers Ratio Scale (BBRS). Benefits of and barriers to PA were assessed using the Exercise Benefits and Barriers Ratio Scale. ${ }^{28}$ Women answered questions related to their personal beliefs about exercise. One example question includes, "Exercise takes too much of my time." Answers range from "strongly agree" to "strongly disagree." Scores range from 43-172, and a higher score indicates more perceived benefits of exercise in relation to perceived barriers to exercise. This questionnaire is reliable and valid for use in adult women ${ }^{28,29}$ and demonstrated good internal consistency (Cronbach's alpha $=.80$ ) in this study sample.

Self-Worth. Self-worth was assessed using the Global Self-Worth Scale of the Adult Self-Perception Profile, which measures global perceptions of self-worth independent of any particular domain. ${ }^{30}$ For example, one question states: "Some adults like the kind of person they are BUT other adults would like to be someone else." The scale includes 9 items, and responses range from "really true for me" to "sort of true for me." Scores range from 1-4, and higher scores indicate higher self-worth. This questionnaire is reliable and valid for use in adult women $^{30}$ and demonstrated high internal consistency (Cronbach's alpha $=.83)$ in this study sample.

Interviews. WBA participants were contacted via phone up to 3 times to schedule an interview. In addition, 1 e-mail was sent to WBA participants to schedule interviews. Interviews were audio recorded and transcribed by members of the research team. Interviews lasted between 15 and 35 minutes. Women were asked questions related to their 1) current PA participation, 2) perceived benefits of and barriers to PA, 3) perceived social support, 4) self-worth and quality of life, 5) motivations for and perceptions of PA, 6) goal setting, 7) self-efficacy for participating in PA, and 8) reflections after WBA. Example questions targeting self-worth, for instance, included: Did your participation in Women Bound to be Active impact your self-worth? If yes, how? How do you think the changes you described relate to your participation in physical activity?

\section{Data Analysis}

Quantitative. Mixed-model repeated-measures ANOVAs were conducted to examine the effects of WBA on PA participation, BMI, self-worth, and benefits relative to barriers of $\mathrm{PA}$, and to examine whether the effects were the same for the completer and noncompleter groups. Partial Eta Square ${ }^{31}$ was calculated and reported as a measure of effect size, ${ }^{32}$ where Partial Eta Square of 0.04 is typically considered as a small effect size, 0.25 as a medium effect size, and 0.64 as a large effect size. ${ }^{33}$ All analyses were conducted using SPSS 18.

Qualitative. Interviews were transcribed verbatim into Microsoft Word 2007 (Microsoft Corporation, Redmond,
WA) from digital audio recordings of phone interviews. Transcripts of interviews conducted with both completers and noncompleters were uploaded into QSR NVivo 9 (Cambridge, MA, 2010), a qualitative data management and analysis software package. An initial codebook was created using questions from the interview guide. Following initial coding, 3 research team members refined the codebook to ensure that concepts and ideas were consistent with participants' experiences as reported in the interviews. Research team members then used the codebook to guide a second round of axial coding to group conceptually similar incidents into the coding structure as defined in the codebook. Further, research team members used in vivo coding during the axial coding phase to capture unanticipated emergent constructs. Research team members met again to ensure correct coding of themes and data saturation, thus yielding consensus on the final interpretation of the qualitative data. ${ }^{34}$

\section{Results}

Primary intervention findings from the WBA second pilot study have been previously published elsewhere. ${ }^{20}$ Of the 52 women in the second pilot study, a total of 30 women participated in the follow-up study (mean age $51.8 \pm 10.2 ; 61 \%$ Caucasian; $\mathrm{n}=17$ completers, $\mathrm{n}=13$ noncompleters; Table 1).

Regardless of completion status, women who participated in the follow-up study had significantly higher leisure-time PA hours per week and leisure-time PA MET hours per week at baseline compared with those who did not participate in the follow-up study, $P=.02$ and $P=$ .037 , respectively. No statistically significant differences in age, BMI, total PA, occupational PA, self-worth, and ratio of benefits to barriers were observed at baseline between women who participated in the follow-up study and those who did not. For women who participated in the follow-up study, there were no statistically significant differences in age, BMI, PA levels, self-worth, and ratio of benefits to barriers at baseline between completers and noncompleters, with effect sizes measured using Cohen's $d$ (Cohen, 1988) ranging from low (around 0.4) for BMI, total PA, self-worth, and ratio of benefits to barriers to medium for age $(d=0.59)$, leisure-time PA $(d=0.73)$, and occupational PA $(d=0.78)$. On average, completers participated in approximately 14.9 of $20 \mathrm{WBA}$ meetings $(75 \%)$, while noncompleters participated in approximately 7.1 meetings (35.4\%).

\section{Body Mass Index (BMI)}

A significant time $\times$ group interaction on BMI was observed $[F(1,19)=4.63, P=.045$, Partial Eta Square $=$ $0.20]$ (Table 2). The average BMI of women in the completer group decreased from $31.87 \pm 6.81$ at baseline to $29.83 \pm 6.29$ at 1-year follow-up while the average BMI of those in the noncompleter group increased from 34.83 \pm 7.74 at baseline to $36.27 \pm 7.96$ at 1-year follow-up. 
Table 1 Completer and Noncompleter Descriptive Characteristics

\begin{tabular}{lccc}
\hline Variable & $\begin{array}{c}\text { Completer } \\
(\mathbf{n}=\mathbf{1 7})\end{array}$ & $\begin{array}{c}\text { Noncompleter } \\
(\mathbf{n}=\mathbf{1 3})\end{array}$ & Total $\mathbf{( N = 3 0 )}$ \\
\hline Age (years) & & & \\
$\quad$ Mean (SD) & $52.5(10.8)$ & $50.7(9.5)$ & $51.8(10.2)$ \\
Race & 14 & 8 & 22 \\
$\quad$ Caucasian & 3 & 3 & 6 \\
African American & - & 2 & 2 \\
Missing & 3 & & 3 \\
Education & 2 & 0 & 4 \\
High school & 1 & 2 & 3 \\
Some college & 5 & 2 & 7 \\
2-year degree & 4 & 2 & 9 \\
Bachelor's degree & 2 & 5 & 4 \\
Graduate/Professional degree & & 2 & \\
Missing & 0 & & 0 \\
Income (per year) & 2 & 0 & 5 \\
$<$ \$20,000 & 3 & 3 & 5 \\
\$20,000-\$40,000 & 10 & 2 & 5 \\
\$41,000-\$60,000 & 2 & 5 & 5 \\
$>$ \$60,000 & & 3 & \\
Missing & & & \\
\hline
\end{tabular}

${ }^{a}$ No significant demographic differences were detected between groups.

\section{PA Behavior Change}

The variables of total PA hours per week, total PA METhours per week, leisure-time PA hours per week, leisuretime PA MET-hours per week, occupational PA hours per week, and occupational PA MET-hours per week were $\log$ transformed to correct the skewness.

Leisure-Time PA. A significant completer and noncompleter group difference in leisure-time PA hours per week was observed at follow-up $[F(1,18)=4.64, P=.045$, Partial Eta Square $=0.21]$. On average the completers reported significantly higher leisure-time PA hours per week than the noncompleters. Although no time effect (Partial Eta Square $=.001)$ or time $\times$ group interaction (Partial Eta Square = .09) were observed, the completers displayed a trend of continued increases in leisure-time PA hours per week from baseline (.92 \pm 1.14 in log form) to 1 -year follow up $(1.25 \pm .69)$, while the noncompleters displayed a trend of continued decreases (from $.10 \pm .90$ to $-.21 \pm 1.97)$. The analysis results for leisure-time PA MET hours per week revealed similar patterns as the leisure-time PA hours per week.

Total PA and Occupational PA. No significant effects of time, group and time $\times$ group interaction on total PA and occupational PA were observed.

Overall Changes in PA: Qualitative Data. Before WBA, most completers and noncompleters reported little to no PA, or sporadic PA. One year after WBA, completers reported higher motivation for PA and more consistent PA than noncompleters. Many of the completers reported being more active during WBA, and though they felt their activity had decreased since the program, they thought that, compared with baseline, their activity had increased.

"I think during WBA I got a lot more consistent with the activities I was already doing, and I tried a couple new activities."

"I [am] pretty consistent more so now then I was right afterwards. And I definitely tried some new activities since then. So, I'm still staying active."

Noncompleters provided less detail about their engagement in PA during WBA, with several simply stating "yes" when asked if their level of activity increased during the program. Most noncompleters reported they were not engaging in PA at follow-up. One noncompleter described her PA as "hit or miss."

\section{Benefits and Barriers}

A significant time $\times$ group interaction was observed $[F(1$, $19)=5.04, P=.037$, Partial Eta Square $=0.21]$ for the ratio of benefits to barriers of PA. The average ratio of benefits to barriers of PA for the completers increased slightly from baseline $(54.2 \pm 16.84)$ to 1 -year follow-up (56.53 \pm 18.17 ), while the average ratio of benefits to barriers for the noncompleters decreased significantly from baseline $(60.17 \pm 13.79)$ to 1 -year follow-up $(47.83 \pm 11.27)$. 


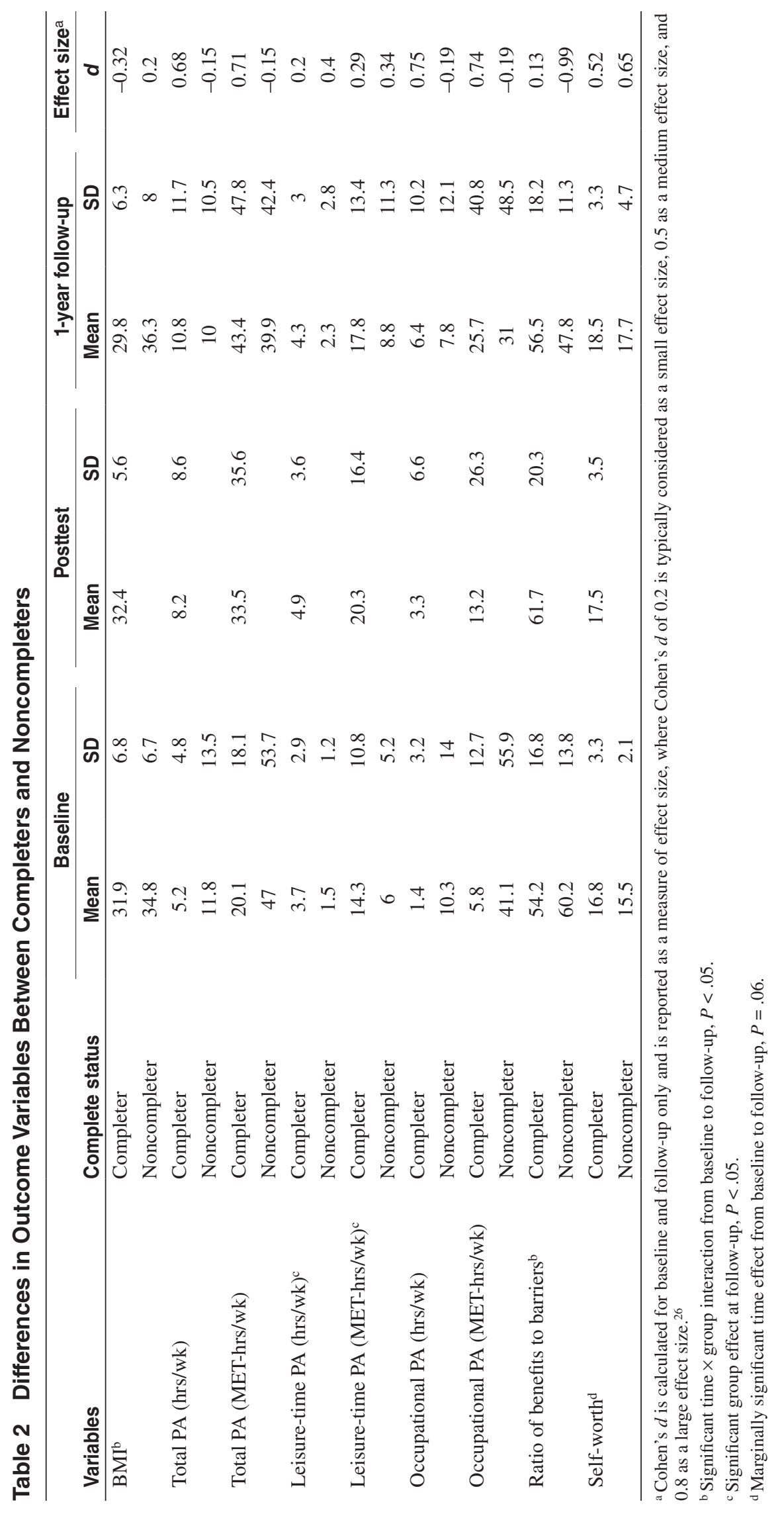


Benefits of PA. Overall women from both groups cited health, wanting to feel good, stress relief, and weight management as the main benefits of PA. Though many completers included weight management and health in their descriptions of the personal benefits of PA, they also discussed the benefits in terms of their self-worth and quality of life. Noncompleters, on the other hand, more often cited solely weight management, appearance, or health as their personal benefits. One completer stated, "Trying to stay healthy," while another stated, "Health, increasing confidence and self-worth, and then appearance is the third." Similarly, another completer said, "Health, reduction of stress, and probably I want to fit in my clothes." One completer tied PA to her overall quality of life, while other completers mentioned personal self-satisfaction, feeling good, and enjoying life. A noncompleter named weight loss and body image as a benefit of PA: "Weight loss; my body image." Another noncompleter remarked, "Health benefits and appearance, sounds a little vain but appearance."

Breaking Barriers to PA. Completers often reported time as their most salient barrier to regular participation in PA. One completer said, "Time is still my biggest, my most limited resource." Many completers also reported having injuries or physical ailments impeding their participation in PA. For example, one woman said, "Time and I do have a little bit of a knee problem."

Despite being challenged by barriers to PA, completers reported that WBA provided them with strategies for overcoming barriers. One woman shared that she was active while her kids were participating in activity. “... During [my kids'] track practice I'm able to exercise while they are exercising. So it keeps me consistent because they have to go Monday through Thursday." Another completer used reading as a tool to continue to learn different activities and strategies for overcoming barriers. "When it gets really cold I'm not very good about getting on the treadmill versus walking outside.... It seems like I'm always trying to read something new that would help me [stay active]."

Noncompleters also often noted time as a major barrier to their participation in PA. A noncompleter suggested, "a magic wand that would give me more time and energy," while other noncompleters discussed time limitations related to competing commitments, such as work. Noncompleters, however, discussed lack of motivation as another major barrier to a greater degree than completers. Women often directly cited "lack of motivation," while others simply referred to their difficulty "just sticking with it." One noncompleter characterized her lack of motivation rhetorically:

"How do I not come home and fall into a rut, but how do I get up and do something? That is what I need motivation with."

Most noncompleters reported more passive strategies to overcoming barriers compared with completers.
One noncompleter reported "mental preparation" as her strategy, and another stated, "I actually have broken through some barriers, but I have chosen not to do anything with it." However, one noncompleter used a similar strategy as a completer to assure that she participated in regular PA. “. . . Instead of going home, I bring my clothes with me and go straight from work to the track and walk while I am waiting for [my son to finish football practice]."

\section{Self-Worth}

A marginally significant time effect on self-worth was observed $[F(1,19)=3.9, P=.06$, Partial Eta Squared $=$ 0.17]. No significant effects of group and time $\times$ group interaction on self-worth were observed from baseline to follow-up. Both completers and noncompleters reported a significant increase in self-worth from baseline to 1-year follow-up.

Although only marginally significant changes in self-worth at 1-year follow-up were observed, women reported changes in the way they felt about themselves and PA. Completers believed that the program had a positive impact on their self-worth. They reported a renewed interest in themselves, principally in ensuring that they dedicated time and energy to meeting their own needs.

"You've got to make time for yourself in order to make time for the exercise."

"I used to focus on everybody else...now I take time for myself and make sure I go to the gym and exercise."

Other completers reported that WBA "helped me to focus more on myself," and "made me think more importantly about myself."

In addition, some of the completers reported that gains in their self-worth were a result of increased confidence (self-efficacy) for PA and other areas of their lives. One participant reported that, "through WBA I got a lot more confident so I became active." Another said, "I just felt better about myself. You know, it's like I feel more confident." Similarly, another participant reported that before her participation in WBA, she avoided telling others that she was participating in WBA, but as a result of the program, she gained the confidence to tell everybody: "Now I talk to everybody and I realize that it's not a thing that has a beginning and an end. It's a lifestyle; it's forever."

Though noncompleters' responses demonstrated an increased understanding of the role of self-worth on how women view themselves and PA, noncompleters, compared with completers, did not apply this understanding to their own lives and their participation in PA.

One noncompleter said, "I don't feel negative about myself. I just have chosen not to do anything ... I am not there yet." 
Another non-completer who described her PA participation since WBA as "zero," discussed how her self-worth related to PA in general terms: "Probably a lot if you see yourself as more valuable, you probably take the time for it to be more active."

"When I am doing it [PA], I am more self-motivated and I am prideful. I guess ... the reason why I don't do it [PA] is because there was change in my physical body but not enough, in my mind, that was acceptable to me."

\section{Perceptions of PA and Self-Worth}

Most completers shared that they had changed perceptions of PA since participating in WBA. These new perceptions seemed to help women feel better about themselves and become more accepting of themselves.

"It doesn't have to be an extreme all or nothing kind of participation . . . because I've learned to accept that fact that ... it's something that has to be for life ... and there is kind of no such thing as failure."

"It's like I look for an opportunity to be active instead of avoiding physical exertion."

"I think it helped me become less judgmental of myself by looking at things that other people had versus, 'she's fat' [or] 'you know she's skinny'; it's not all about the body shape."

Completers' new perceptions about PA helped some to change their perceptions about the importance of weight in relation to participation in PA. Although completers still cited weight management and appearance as some of their benefits of being active and reasons to be active, most also acknowledged, after participating in WBA, that weight management did not have to be the only reason to participate in PA. This shift in perception about PA helped completers to discover other motives for PA. "The biggest impact that was made on me [by WBA] was get off the scale and don't worry about the number." This was echoed by another participant who believed that "getting off the scale is the whole not worrying about losing weight, [but] worrying about simply being more active." Another participant characterized this concept as, "I think previously the perception was more of weight loss. . . . Now it's more of just simply being healthier."

Other completers found use of the pedometer and exposure to new activities to be valuable program components for changing perceptions toward physical activity.

"I was pretty stuck in what I had done before and then what I thought I could do in the future. . . . Trying new things and stuff kinda opened things up ...."

"I thought I was maybe more active than I was and then the numbers showed no ... so that motivated me a lot."
Noncompleters did not share the change in perceptions to PA participation as the completers did. One noncompleter explained her lack of change in her perceptions: "I don't think I attended regularly or consistently enough."

\section{Social Support}

Both completers and noncompleters reported that their family members, particularly their husbands, supported them in being physically active. Children, friends, coworkers, and social groups (eg, faith community) were also identified as sources of social support. Responses from completers regarding the necessity of social support were mixed; some reported that they needed social support as a motivator, "It makes it easier if you have someone," while others reported that they were motivated on their own, "No, I think that I do it for myself." Most noncompleters reported that they did need social support to be physically active; one stated that, "It is much easier to do things with others or somebody else than it is to do it by yourself."

Completers and noncompleters both reported that they also found social support in WBA itself. Most often, this social support was characterized as finding common ground or recognizing shared experiences with other participants. One completer found that "the interaction with the women was very rewarding."

Completers spoke about the relationships that they built during the program, and believed that continued social support from their personal social networks would keep them engaged in and be motivated for PA. "They [the women in the program] were great as an initial "get going," but then I kinda went on my own and family became more of my support." They also reported that they learned how to reach out and ask for support. "I learned this skill ... of reaching out and asking for support or looking for support ... that has stayed with me since the program." Alternatively, some completers shared that they realized that they needed to be accountable for their own PA behaviors rather than depending on others' support to maintain their behaviors. "[The other women in the program] made me feel motivated during ... and since I don't really feel those people are motivating me on the days that I am active. . . The motivation comes from within."

Noncompleters reported that they enjoyed the social support because they felt they could connect with others similar to themselves. "Just listening to them and their trials and tribulations meant a lot." However, social support from the group did not appear to impact their PA participation.

\section{Discussion}

This study used a mixed-methods approach to examine the long-term impact of an innovative, lifestyle PA intervention designed to improve women's PA participation and self-worth long-term. Qualitative interviews 
augmented quantitative data to better understand why women maintained or failed to maintain PA at 1-year follow-up.

No significant differences in total PA and occupational PA were observed from baseline to 1-year follow-up. However, completers had significantly more leisure-time PA at follow-up than noncompleters and demonstrated a positive trend in leisure-time PA over time. These results suggest that WBA had a greater impact on leisure-time PA compared with other types of PA which is consistent with the lifestyle focus of the WBA intervention. Research provides evidence that interventions that focus on moderate-intensity lifestyle PA (eg, leisure-time PA) have greater success increasing women's PA compared with interventions focusing on structured activity. ${ }^{35}$ Lifestyle PA interventions allow women to save time by integrating PA into their lives and may, therefore, be more successful than structured programs. Research has provided evidence that lifestyle approaches to PA behavior change have substantial health benefits, including reduced risk of cardiovascular disease. ${ }^{36} \mathrm{WBA}$ used an unstructured approach to PA participation in targeting women's lifestyle PA and providing women tools and strategies to integrate PA into their lifestyles. Completers, due to greater participation in WBA, may have learned more strategies for increasing PA using this unstructured approach, as evidenced by their positive results related to leisure-time PA and BMI compared with the noncompleters.

Noncompleters reported low levels of leisure-time PA from baseline to follow-up, but high levels of occupational PA at baseline and follow-up. The demands of their jobs may have contributed to their inability to complete WBA and lack of motivation to participate in increased leisure-time PA. ${ }^{37}$ Examples of noncompleters' occupations included researcher, registered nurse, and pharmacist, jobs that generally require higher levels of activity (eg, walking, standing, lifting) compared with many of the jobs reported by completers (eg, retired, office work).

Various factors may have contributed to the differences we observed in leisure-time PA between completers and noncompleters, including the ability to overcome barriers to PA. Specifically, completing WBA was associated with an increased ability to overcome barriers to PA. Women who completed the program reported more benefits of PA at follow-up compared with baseline, while women who did not complete the program reported more barriers relative to benefits of PA at follow-up. One of the major components of the book club was to help women become aware of their barriers and strategize ways to overcome those barriers to maintain PA, suggesting that a book club approach may be a viable method in this regard. Previous research has shown that perceived barriers are inversely associated with PA participation and teaching women behavioral skills to overcome barriers to PA may lead to better adherence and higher PA levels. ${ }^{38}$

Noncompleters most often cited time and other factors (eg, work) as barriers to their participation in PA. In some cases lack of time led to decisions to drop out of the program. Attrition in this study (44\%) is consistent with other research indicating that as many as $50 \%$ of participants drop out of programs within the first 3-6 months. ${ }^{39}$ Most health benefits are not realized until at least 6 months of continuous participation in PA; therefore, this high attrition rate often results in failure to attain the health benefits of PA. ${ }^{40,41}$ Noncompleters' increases in barriers to PA suggest that these women may not have participated in WBA long enough to realize the physical, psychosocial, and emotional benefits of PA. ${ }^{6}$ Additionally, limited participation in WBA may have affected the extent to which noncompleters learned strategies to overcome their barriers and continue to participate in PA. Additional efforts to limit barriers are needed to mitigate attrition in PA programs. Such efforts may be critical to ensuring that more women continue to participate in PA after programs end and achieve PA-related health benefits. A greater focus on time management and self-regulation strategies may help women more effectively overcome barriers to their PA participation. In addition, examining alternate methods of program delivery may help women to better adhere to PA programs. The Internet, for example, may be a viable alternative, while further alleviating barriers common in face-to-face programs (eg, time, synchronous participation, driving to program sites). Internet-based PA programs have revealed promising results ${ }^{42}$ and have been particularly attractive to women. ${ }^{43}$ Future trials testing the feasibility and effectiveness of the book club approach for promoting long-term PA adherence in women should explore the Internet as a means of implementing WBA.

Both completers and noncompleters reported increases in their self-worth from baseline to follow-up. Women who reported improvements in self-worth often related their increases to a renewed focus on themselves, which allowed them to participate in PA. Some completers related improvements in their self-worth to increased confidence to participate in PA. Self-efficacy, or situation-specific self-confidence, ${ }^{10}$ is a well-known predictor of self-worth. ${ }^{12,13}$ Despite similarities in self-worth as evidenced in our quantitative findings, completers, compared with noncompleters, described a sustained impact of improved self-efficacy and selfworth on their PA participation at follow-up. After WBA noncompleters had an increased understanding of what valuing and prioritizing oneself means, but were unable to apply this to their own lives and view themselves with increased self-worth in terms of their participation in PA. These results support the differences in leisure-time PA observed between the 2 groups at follow-up, suggesting that noncompleters may not have prioritized themselves enough to overcome barriers to participating in WBA and, ultimately, leisure-time PA.

WBA used self-worth enhancing strategies to encourage women to set goals they enjoy pursuing, rather than goals they think they should pursue. WBA completers began to acknowledge the benefits of PA related to their quality of life, and how they feel about themselves (self-worth) rather than their appearance. Compared with noncompleters, completers more often 
described nonweight related benefits and perceptions of PA, suggesting that they began to internalize their PA participation and move away from extrinsically motivating reasons for PA. Previous research has demonstrated that different types of PA goals may have differential impact on women's ability to maintain PA long-term. For example, Segar and colleagues ${ }^{8}$ have provided evidence that women who set intrinsically motivated goals for PA (eg, stress reduction, sense of well being) are more likely to continue to participate in PA over time compared with women who set extrinsically motivated goals (eg, weight loss, health benefits). Encouraging PA participation in women through self-worth enhancement and setting intrinsically motivating goals may be particularly important for sustained PA participation in women, and our results suggest that additional research in this area is warranted.

Women's need for social support to be active was mixed. Many of the women who completed the program reported that they did not need social support to be active, indicating that increased intrinsic motivation helped them to feel autonomous in their participation in PA. Many completers, however, also reported that social support was important to their continued participation in PA. Vrazel and colleagues ${ }^{2}$ have noted that social support is one of the most consistent positive correlates of PA. Women not only found support with the women in the book club, but they were also able to access increased social support after the program ended. Noncompleters, on the other hand, did not report increased social support after the program ended. Consistent with previous literature, ${ }^{44}$ social support from family members, particularly husbands, was important to both completers and noncompleters. Therefore, teaching women how to access social support may be specifically important for those women who do not have support for PA from family members. This factor should be considered when developing social support enhancing strategies in future PA interventions tailored to women.

\section{Limitations}

The findings from this study should be interpreted in the context of its limitations. First, self-report was used to measure women's PA participation at all time points. Although the MAQ has established validity and reliability in this population, limitations related to recall are inherent in self-report instruments. In addition, the changes in perceptions of PA that women reported after WBA may have led to differences in reporting between baseline and follow-up. For example, women may have better recalled lifestyle activities at postintervention and follow-up compared with baseline because of their increased PA knowledge. Future studies should explore both subjective and objective methods of measuring long-term and intervention PA outcomes in women.

Second, self-efficacy and social support were both addressed qualitatively; however, this study did not include quantitative measures of either construct.
Not surprisingly, self-efficacy and social support both emerged as important correlates of women's PA during qualitative interviews. Therefore, future studies should include quantitative measures of both self-efficacy for PA and social support. Third, although no statistically significant differences between completers and noncompleters were observed at baseline, the effect size as shown by Cohen's d was medium to high for leisure-time PA and occupational PA, indicating true differences in these variables may likely exist at baseline. This implies that completers and noncompleters may have had different PA behaviors at baseline already and they might be likely representing different cohorts. Due to the small sample size and nature of the current study (eg, a communitybased intervention and lack of a control group), our ability to detect meaningful differences between completers and noncompleters, while adjusting for potential confounders, with adequate statistical power was limited. Future studies testing the effectiveness of the book club approach on women's PA participation should include a randomized control trial design.

\section{Conclusions}

This study contributes meaningfully to existing literature by providing insight into factors impacting long-term PA adherence using both quantitative and qualitative data from completers and noncompleters of a book club intervention for women. Understanding how completers and noncompleters differ and why women drop out of PA programs are imperative to the success of future PA programs (both in the design and delivery of programs). Such knowledge may provide us with a better understanding of what factors contribute to women's active leisure choices. Our findings reinforce the need for further research that 1) promotes time management and selfregulation strategies to limit barriers to PA, 2) examines the role of self-worth on women's long-term participation in PA, and 3) further examines the effectiveness of teaching women how to proactively access social support to facilitate PA adherence. The findings of this study not only highlight the importance of developing innovative strategies to limit program attrition, but also substantiate the continued examination of the book club format as a means for increasing self-worth and long-term PA participation among adult women.

\section{References}

1. Centers for Disease Control and Prevention (CDC). U.S. physical activity statistics. Retrieved from http://apps.nccd. cdc.gov/PASurveillance/DemoComparev.asp. Updated January 8, 2010. Accessed December 28, 2010.

2. Vrazel J, Saunders RP, Wilcox S. An overview and proposed framework of social-environmental influences on the physical-activity behavior of women. Am J Health Promot. 2008;23(1):2-12. PubMed doi:10.4278/ajhp.06070999

3. Marcus BH, Lewis BA, Williams DW, et al. A comparison of internet and print-based physical activity interven- 
tions. Arch Intern Med. 2007;167:944-949. PubMed doi:10.1001/archinte.167.9.944

4. Napolitano MA, Whiteley JA, Papandonatos G, et al. Outcomes from the women's wellness project: a community-focused physical activity trial for women. Prev Med. 2006;43:447-453. PubMed doi:10.1016/j. ypmed.2006.06.011

5. Müller-Riemenschneider F, Reinhold T, Nocon M, Willich SN. Long-term effectiveness of interventions promoting physical activity: a systematic review. Prev Med. 2008;47:354-368. PubMed doi:10.1016/j. ypmed.2008.07.006

6. Conroy MB, Simkin-Silverman LR, Pettee KK, Hess R, Kuller LH, Kriska AM. Lapses and psychosocial factors related to physical activity in early postmenopause. Med Sci Sports Exerc. 2007;39(10):1858-1866. PubMed doi:10.1249/mss.0b013e318137388d

7. Martin MY, Prayor-Patterson H, Kratt P, Kim Y, Person S. Characteristics of insufficiently active hypertensive Black women who volunteer to be in a physical activity promotion intervention: an application of social cognitive theory and the transtheoretical model. Ethn Dis. 2007;17(4):604-610. PubMed

8. Segar ML, Eccles JS, Richardson CR. Type of physical activity goal influences physical activity participation in women. Womens Health Issues. 2008;18(4):281-291. PubMed doi:10.1016/j.whi.2008.02.003

9. Huberty JL, Ransdell LB, Sidman C, et al. Explaining long-term exercise adherence in women who complete a structured exercise program. Res $Q$ Exerc Sport. 2008;79(3):374-384. PubMed

10. McAuley E, Blissmer B. Self-efficacy determinants and consequences of physical activity. Exerc Sport Sci Rev. 2000;28(2):85-88. PubMed

11. Huberty JL, Vener J, Sidman C, et al. Women Bound to be Active: a pilot study to explore the feasibility of an intervention to increase physical activity and self-worth in women. Women Health. 2008;48(1):83-101. PubMed doi:10.1080/03630240802132120

12. Elavsky S. Physical activity, menopause, and quality of life: the role of affect and self-worth across time. Menopause. 2009;16(2):265-271. PubMed doi:10.1097/ gme.0b013e31818c0284

13. McAuley E, Mihalko SL, Bane SM. Exercise and self-esteem in middle-aged adults: multidimensional relationships and physical fitness and self-efficacy influences. J Behav Med. 1997;20(1):67-83. PubMed doi:10.1023/A:1025591214100

14. Shavelson RJ, Hubner JJ, Stanton GC. Self-concept: validation of construct interpretations. Rev Educ Res. 1976;46:407-441.

15. Fox KR, Corbin CB. The Physical Self-Perception Profile: development and preliminary validation. J Sport Exer Psychol. 1989;11:408-430.

16. Gothe NP, Mullen SP, Wójcicki TR, et al. Trajectories of change in self-esteem in older adults: exercise intervention effects. J Behav Med. 2011;34(4):298-306. PubMed doi:10.1007/s10865-010-9312-6

17. Elavsky S, McAuley E. Exercise and self-esteem in menopausal women: a randomized controlled trial involving walking and yoga. Am J Health Promot. 2007;22(2):83-92. PubMed doi:10.4278/0890-1171-22.2.83

18. Strelan P, Mehaffey SJ, Tiggeman M. Self-objectification and esteem in young women: the mediating role of reasons for exercise. Sex Roles. 2003;48(1/2):89-95. doi:10.1023/A:1022300930307

19. Segar M, Spruijt-Metz D, Nolen-Hoeksema S. Go figure? Body-shape motives are associated with decreased physical activity participation among midlife women. Sex Roles. 2006;54(3/4):175-187. doi:10.1007/s11199006-9336-5

20. Huberty JL, Vener J, Ransdell LB, Schulte L, Budd MA, Gao Y. Women Bound to be Active (years 3 and 4): can a book club help women overcome barriers to physical activity and improve self-worth? Women Health. 2010;50:88106. PubMed doi:10.1080/03630241003601103

21. Huberty JL, Vener J, Schulte L, Roberts SM, Stevens BA, Ransdell LB. Women Bound to Be Active: one year follow-up to an innovative pilot intervention to increase physical activity and self-worth in women. Women Health. 2009;49:522-539. PubMed doi:10.1080/03630240903424020

22. Marcus BH, Rossi JS, Selby VC, Niaura RS. Self-efficacy and the stages of exercise behavior change. Res $Q$ Exerc Sport. 1992;63(1):60-66. PubMed

23. Bandura A. Social foundations of thought and action. Englewood Cliffs, NJ: Prentice Hall; 1986.

24. Howley ET, Franks BD. Health fitness instructor's handbook: health status questionnaire. Champaign, Ill: Human Kinetics; 1992.

25. Spencer EA, Appleby PN, Davey GK, Key TJ. Validity of self-reported height and weight in 4808 EPIC-Oxford patients. Public Health Nutr. 2002;5(4):561-565. PubMed

26. Kriska AM, Knowler WC, LaPorte RE, et al. Development of questionnaire to examine relationship of physical activity and diabetes in Pima Indians. Diabetes Care. 1990;13(4):401-411. PubMed

27. Vuillemin A, Oppert JM, Guillemin F, et al. Selfadministered questionnaire compared with interview to assess one-year physical activity. Med Sci Sports Exerc. 2000;32(6):1119-1124. PubMed

28. Sechrist KR, Walker SN, Pender NJ. Development and psychometric evaluation of the exercise benefits/barriers scale. Res Nurs Health. 1987;10(6):357-365. PubMed

29. El Ansari W, Lovell G. Barriers to exercise in younger and older non-exercising adult women: a cross sectional study in London, United Kingdom. Int J Environ Res Public Health. 2009;6(4):1443-1455. PubMed doi:10.3390/ ijerph6041443

30. Messer B, Harter SV. Manual for the adult self-perception profile. Denver, CO: University of Denver Press; 1986.

31. Pierce CA, Block RA, Aguinis H. Cautionary note on reporting eta-squared values from multifactor designs. Educ Psychol Meas. 2004;64:916-924. doi:10.1177/0013164404264848

32. Cohen J. Statistical power analysis for the behavioral sciences. 2nd ed. Hillsdale, NJ: Lawrence Erlbaum Associates; 1988.

33. Ferguson CJ. An effect size primer: a guide for clinicians and researchers. Prof Psychol Res Pr. 2009;40(5):532538. doi:10.1037/a0015808

34. Strauss A, Corbin J. Basics of qualitative research. 2nd ed. Thousand Oaks, CA: Sage Publications; 1998.

35. Dunn AL, Andersen RE, Jakicic JM. Lifestyle physical activity interventions: history, short- and longterm effects, and recommendations. Am J Prev Med. 1998;15(4):398-412. PubMed doi:10.1016/S07493797(98)00084-1 
36. Knowler WC, Barret-Connor E, Folwer SE, et al. Reduction of the incidence of type 2 diabetes with lifestyle intervention or metformin. N Engl J Med. 2002;346(6):393403. PubMed doi:10.1056/NEJMoa012512

37. Caban-Martinez AJ, Lee DJ, Fleming LE, et al. Leisuretime physical activity levels of the US workforce. Prev Med. 2007;44(5):432-436. PubMed doi:10.1016/j. ypmed.2006.12.017

38. Cerin E, Leslie E, Sugiyama T, Owen N. Perceived barriers to leisure-time physical activity in adults: an ecological perspective. J Phys Act Health. 2010;7(4):451-459. PubMed

39. Findorff MJ, Wyman JF, Gross CR. Predictors of long-term exercise adherence in a community-based sample of older women. J Womens Health (Larchmt). 2009;18(11):1769_ 1776. PubMed doi:10.1089/jwh.2008.1265

40. Ainsworth BE. Physical activity patterns in women. Phys Sportsmed. 2000;28(10):2. PubMed doi:10.3810/ psm.2000.10.1243
41. Annesi JJ. Effects of minimal exercise and cognitive behavior modification on adherence, emotion change, self-image, and physical change in obese women. Percept Mot Skills. 2000;91(1):322-336. PubMed doi:10.2466/ pms.2000.91.1.322

42. Marcus BH, Ciccolo JT, Sciamanna CN. Using electronic/ computer interventions to promote physical activity. $\mathrm{BrJ}$ Sports Med. 2009;43(2):102-105. PubMed doi:10.1136/ bjsm.2008.053744

43. Vandelanotte C, Spathonis KM, Eakin EG, Owen N. Website-delivered physical activity interventions. Am J Prev Med. 2007;33(1):54-64. PubMed doi:10.1016/j. amepre.2007.02.041

44. Seefeldt V, Malina RM, Clark MA. Factors affecting levels of physical activity in adults. Sports Med. 2002;32(3):143168. PubMed doi:10.2165/00007256-200232030-00001 
Copyright of Journal of Physical Activity \& Health is the property of Human Kinetics Publishers, Inc. and its content may not be copied or emailed to multiple sites or posted to a listserv without the copyright holder's express written permission. However, users may print, download, or email articles for individual use. 